\title{
Influence of Dilution Rate on Enzyme Synthesis in Aspergillus niger in Continuous Culture
}

\author{
By A. M. L. NG, J. E. SMITH AND A. F. MCINTOSH \\ Department of Applied Microbiology, Strathclyde University, Glasgow GI IXW
}

(Received 24 September 1973; revised 23 November 1973)

\begin{abstract}
SUMMARY
Aspergillus niger was grown in continuous culture under steady-state conditions in citrate-limiting or glucose-limiting medium. The specific activities of hexokinase, phosphofructokinase, pyruvate kinase, fructose diphosphatase, 6-phosphogluconate dehydrogenase and, to a limited extent, citrate synthase under citrate limitation remained at a relatively constant steady-state level irrespective of the dilution rate $\left(0.01\right.$ to $\left.0.05 \mathrm{~h}^{-1}\right)$. Increase in dilution rate led to an increase in the specific activities of aconitase, NAD (P) isocitrate dehydrogenase, malate dehydrogenase, and glucose-6phosphate dehydrogenase in both citrate and glucose limiting culture, and to an increase in citrate synthase, hexokinase, phosphofructokinase, pyruvate kinase, and 6-phosphogluconate dehydrogenase only in glucose limitation. A decrease in specific activity with increasing dilution rate occurred with isocitrate lyase in both citrate and glucose limitation and for fructose diphosphatase only in glucose limitation. The specific activity of malate synthetase showed a peak activity in the middle range of dilution rates.
\end{abstract}

\section{INTRODUCTION}

Most studies on the regulation of enzyme synthesis in filamentous fungi have been carried out using the batch cultivation system. During growth in batch culture the environmental factors which influence enzyme activity may change in a continuous and often unpredictable manner. By utilizing continuous flow culture it is possible to maintain these variables at constant values and to permit more rigorous examination of the effects of individual environmental factors on the physiology of the organism. It is surprising that continuous culture techniques have not been more widely exploited in studying enzyme regulation in microorganisms. Such studies as have been made have largely been with unicellular microorganisms such as yeasts and bacteria (Clarke \& Lilly, 1969; Dean, 1972), although limited studies have been made on glucose catabolizing enzymes in Aspergillus nidulans (Carter \& Bull, 1969; Bainbridge et al. 1971).

This paper is concerned with the influence of dilution rate (i.e. specific growth rate) on selected enzymes of the tricarboxylic acid cycle, the glyoxylate by-pass and the EmbdenMeyerhof-Parnas (EMP) and pentose phosphate (PP) pathways in Aspergillus niger growing in citrate limiting or glucose limiting chemostat culture. It has previously been shown that filamentous growth of Aspergillus niger can be routinely achieved during continuous cultivation under citrate or glucose limitation (Ng, Smith \& McIntosh, 1973a).

\section{METHODS}

Organism. Aspergillus niger van Tieghem (IMI 4I873) was used throughout and was routinely maintained as previously described (Galbraith \& Smith, 1969a).

Apparatus and cultural conditions. Fermenter culture was in an $\mathrm{AB}$ Biotech laboratory 
fermenter (Maria Skolgata, 83 II652 Stockholm, Sweden) using a working volume of $2.5 \mathrm{l}$ and a temperature of $30^{\circ} \mathrm{C}$. Agitation was provided by a flat-blade impeller operating at $700 \mathrm{rev} . / \mathrm{min}$ and aeration by a small aquarium pump discharging an airflow rate of $\mathrm{r} \cdot 2 \mathrm{l} / \mathrm{min}$. $\mathrm{pH}$ was automatically controlled at 4 by the addition of $2 \mathrm{~N}-\mathrm{HCl}$ or $2 \mathrm{~N}-\mathrm{NaOH}$, and foaming controlled by the addition of polypropyleneglycol P2000 (Dow Chemical Co.).

The basal mineral (M) medium contained in I l distilled water: $\mathrm{KH}_{2} \mathrm{PO}_{4}, \mathrm{I} \mathrm{g} ; \mathrm{MgSO}_{4} \cdot 7 \mathrm{H}_{2} \mathrm{O}$, $0.25 \mathrm{~g} ; \mathrm{CuSO}_{4} \cdot 5 \mathrm{H}_{2} \mathrm{O}, 0.234 \mathrm{mg} ; \mathrm{FeSO}_{4} \cdot 7 \mathrm{H}_{2} \mathrm{O}, 6 \cdot 32 \mathrm{mg} ; \mathrm{ZnSO}_{4} \cdot 7 \mathrm{H}_{2} \mathrm{O}, \mathrm{I} \cdot \mathrm{I} \mathrm{mg} ; \mathrm{MnCl}_{2} .4 \mathrm{H}_{2} \mathrm{O}$, $3.5 \mathrm{mg} ; \mathrm{CaCl}_{2}, 46.7 \mathrm{mg}$. Citrate limiting medium and glucose limiting medium, respectively, contained $\mathrm{I} 0 \mathrm{~g}$ sodium citrate or $\mathrm{I} O \mathrm{~g}$ glucose as carbon source, and $2 \mathrm{~g}\left(\mathrm{NH}_{4}\right)_{2} \mathrm{SO}_{4}$ as nitrogen source, in $11 \mathrm{M}$ medium.

A mycelial inoculum (70 ml), prepared as previously described (Anderson \& Smith, I97I), was added to the fermenter to initiate growth. Steady state was judged to have been achieved when the mycelium dry weight and residual substrate were similar on consecutive daily tests after exchanging about three volumes of the medium.

Analytical methods. Mycelial dry weights were determined by suction filtration, with repeated washing, through previously weighed Whatman No. I filter paper, drying the mycelial pad for $\mathrm{I} 8 \mathrm{~h}$ at $104{ }^{\circ} \mathrm{C}$, cooling in a desiccator, and reweighing. Glucose was assayed using a Schweizerhall glucose oxidase test kit (Unicam Instruments Ltd) and citrate estimated by the method of Saffran \& Denstedt (I948).

Preparation of cell-free extracts. The mycelium was harvested by filtration, washed free of medium, pressed between filter papers to remove excess water and disrupted by means of a glass homogenizer. A ratio of $\mathrm{I} g$ wet weight of mycelium to $\mathrm{Io} \mathrm{ml}$ extraction medium was used. The following extraction media were employed for different enzymes. (i) Tricarboxylic acid cycle enzymes other than citrate synthase: $0 \cdot \mathrm{I}$ M-phosphate buffer, $\mathrm{pH} \mathrm{7.4}$, and 0.I mM-EDTA (Khouw \& McCurdy, I969); (ii) citrate synthase: $0.4 \mathrm{M}-\mathrm{KCl}$ and $20 \%$ ethyl alcohol (Khouw \& McCurdy, I969); (iii) isocitrate lyase and malate synthetase: $0.5 \mathrm{M}$ mannitol, 4 mM-EDTA, $\mathrm{pH} 7 \cdot 0$ (Galbraith \& Smith, I969 $b$ ); (iv) Embden-MeyerhofParnas and pentose phosphate pathway enzymes: $0.05 \mathrm{M}$-tris- $\mathrm{HCl}$ buffer, $\mathrm{pH} 7.0(\mathrm{Ng}$, Smith \& Anderson, 1972).

All operations were carried out between 0 and $4{ }^{\circ} \mathrm{C}$. The homogenate was centrifuged at $800 \mathrm{~g}$ for $\mathrm{to} \mathrm{min}$, the sediment discarded, and the supernatant again centrifuged at $25000 \mathrm{~g}$ for $30 \mathrm{~min}$. The final supernatant was used immediately for enzymic determinations.

Enzyme assays. A Unicam SP 800 spectrophotometer with a constant-temperature cuvette holder and an external recorder was used to measure enzymic activities of cell-free extracts. All assays were carried out at $28^{\circ} \mathrm{C}$. Reactions were started by the addition of the appropriate substrate and activities determined by observing the change in extinction at the appropriate wavelength, recorded continuously for 3 to $5 \mathrm{~min}$, and calculating the result from the linear portion of the graph. Endogenous activity determined from an assay system without the substrates was always subtracted. The concentration of enzyme was chosen so that the change of extinction was not less than $0.010 / \mathrm{min}$ and not more than $0.040 / \mathrm{min}$. Assays were always made in triplicate along with a control lacking enzyme.

Citrate synthase was assayed as described by Srere \& Kosicki (196I), aconitase by Anfinsen (1955), NADP-linked and NAD-linked isocitrate dehydrogenase by Kornberg (1955), $\alpha$-oxoglutarate dehydrogenase by von Tigerstrom \& Campbell (I966), malate dehydrogenase by Ochoa (I955), isocitrate lyase by Dixon \& Kornberg (1959), malate synthetase by Hock \& Beevers (I966), hexokinase by Gibbs \& Turner (1964), phosphofructokinase by Slater (I953), fructose diphosphatase by Rosen (I966), pyruvate kinase by Bucher \& Pfleiderer (1955), and glucose 6-phosphate dehydrogenase and 6-phosphoglucon- 
ate dehydrogenase were assayed as described by Waygood \& Rohringer (I964). Protein was assayed by the method of Lowry, Rosebrough, Farr \& Randall (I95I).

Presentation of enzyme results. One unit of enzyme is defined as the amount of enzyme which converts $\mathrm{I} \mu \mathrm{mol}$ of substrate/min at $25^{\circ} \mathrm{C}$. Specific activity is expressed as units of enzyme/mg protein. The following extinction coefficients were used in calculations : NAD(P)H (nucleotide), $6.22 \times 10^{6} \mathrm{~cm}^{2} / \mathrm{mol}$ at $340 \mathrm{~nm}$ (Horecker \& Kornberg, 1948); aconitase, $3.3 \times 10^{6} \mathrm{~cm}^{2} / \mathrm{mol}$ at $240 \mathrm{~nm}$ (Anfinsen, 1955 ); glyxoylic acid phenylhydrazine, $\mathrm{I} \cdot 7 \times 10^{4} \mathrm{~cm}^{2} /$ mol (Dixon \& Kornberg, I959); mercaptide ion, $\mathrm{I} \cdot 33 \times 10^{7} \mathrm{~cm}^{2} / \mathrm{mol}$ (Hock \& Beevers, I966).

Theoretical considerations. Dilution rate $(D)$ was determined by the ratio of flow rate $(f)$ to culture volume $(v)$, i.e. $D=f / v\left(\mathrm{~h}^{-1}\right)$.

\section{RESULTS}

Under citrate limitation biomass increased with increase in dilution rate up to a maximum of $D=0.042 \mathrm{~h}^{-1}$ (Table I). At $D=0.05 \mathrm{I} \mathrm{h}^{-1}$ biomass tended to decrease sharply while residual citrate increased, indicating that 'wash-out' was occurring. Under glucose limitation at dilution rates between $D=0.020$ and $0.083 \mathrm{~h}^{-1}$, biomass remained relatively constant and residual glucose occurred only at trace levels. Below $D=0.020 \mathrm{~h}^{-1}$ biomass decreased, while above $D=0.083 \mathrm{~h}^{-1}$ biomass also decreased with a concomitant increase in the level of glucose in the medium, indicating the onset of 'wash-out'.

\section{Activities of enzymes of the tricarboxylic acid cycle}

Citrate limitation. The effect of dilution rate under citrate limitation on TCA cycle enzymes is shown in Figs. I $(a)$ and 2(a). Aconitase activity increased appreciably from $D=0.013$ to $0.034 \mathrm{~h}^{-1}$, after which the increase was less abrupt. NADP-linked isocitrate dehydrogenase activity followed a pattern similar to aconitase except that there was only a slight increase in activity when the dilution rate increased from $D=0.034$ to $0.042 \mathrm{~h}^{-1}$. NAD-linked isocitrate dehydrogenase activity was low and was only detectable at $D \geqslant 0.034 \mathrm{~h}^{-1}$; as the dilution rate increased to $D=0.042 \mathrm{~h}^{-1}$, there was a slight increase in activity. $\alpha$-Oxoglutarate dehydrogenase was not detected. Malate dehydrogenase was the most active enzyme of the tricarboxylic acid (TCA) cycle, the activity rising steadily with increasing dilution rate. Citrate synthase activity remained nearly unchanged from $D=0.013$ to $0.034 \mathrm{~h}^{-1}$ but increased somewhat at $D=0.042 \mathrm{~h}^{-1}$.

Glucose limitation. The effect of dilution rate under glucose limitation on TCA cycle enzymes is shown in Figs. I $b$ and $2 b$. Aconitase varied little in activity between $D=0.014$ and $0.034 \mathrm{~h}^{-1}$ but increased sharply at $D=0.045 \mathrm{~h}^{-1}$. A progressive increase in activity of NADP-linked isocitrate dehydrogenase accompanied an increase in dilution rate from $D=0.014$ to $0.034 \mathrm{~h}^{-1}$, after which there was a slight decrease in activity. Activity of NAD-linked isocitrate dehydrogenase was low as compared with that of NADP-linked isocitrate dehydrogenase and increased only slightly with an increase in dilution rate. As in the case of citrate limited culture, $\alpha$-oxoglutarate dehydrogenase could not be detected. The activity of malate dehydrogenase increased approximately twofold as the dliution rate increased from $D=$ 0.014 to $0.045 \mathrm{~h}^{-1}$. Citrate synthase varied directly with the dilution rate. A twofold increase in activity between $D=0.014$ and $D=0.045 \mathrm{~h}^{-1}$ was recorded. Compared with citrate limiting culture, the glucose limiting culture had lower levels of aconitase and, to a lesser extent, malate dehydrogenase and citrate synthase at corresponding dilution rates. 

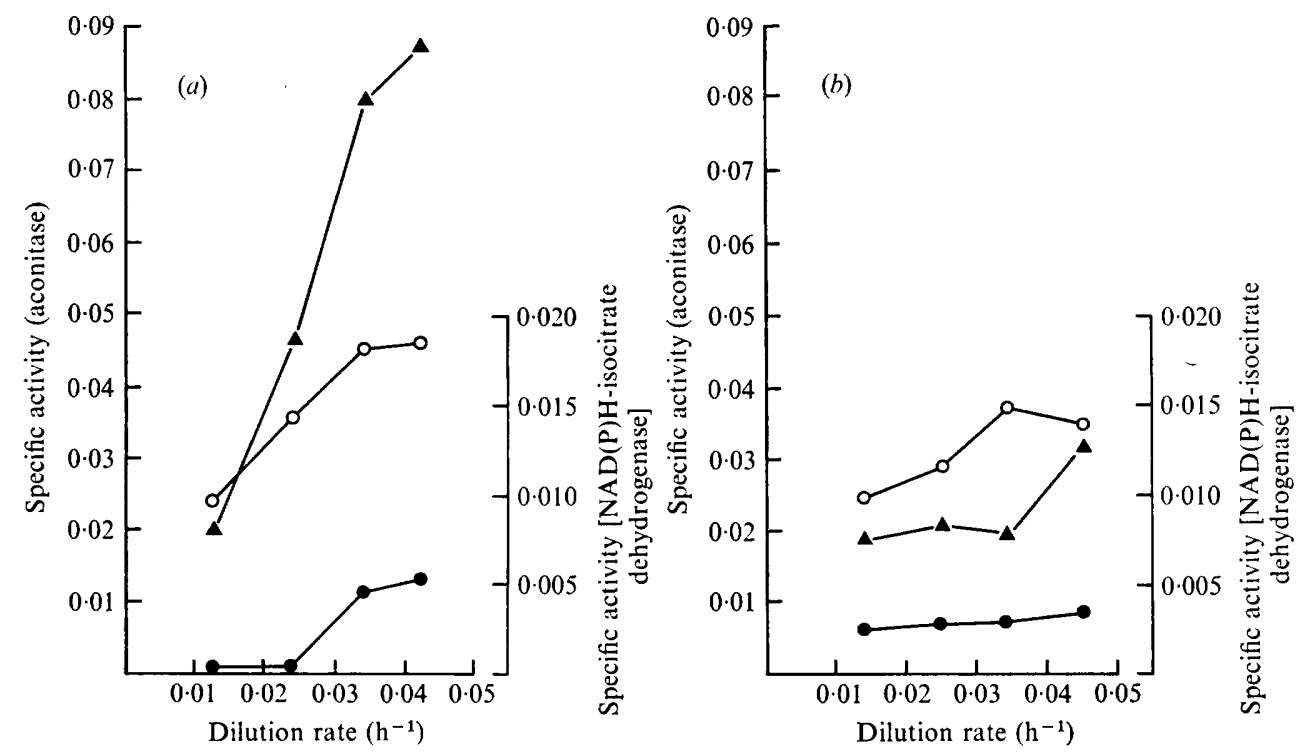

Fig. I. Effect of dilution rate on the activity of aconitase and NAD- and NADP-linked isocitrate dehydrogenase of Aspergillus niger. (a) Citrate limitation; (b) glucose limitation. Specific activity is expressed as units of enzyme/mg protein. $\triangle$, Aconitase; O, NADP-isocitrate dehydrogenase; $\bullet$, NAD-isocitrate dehydrogenase.
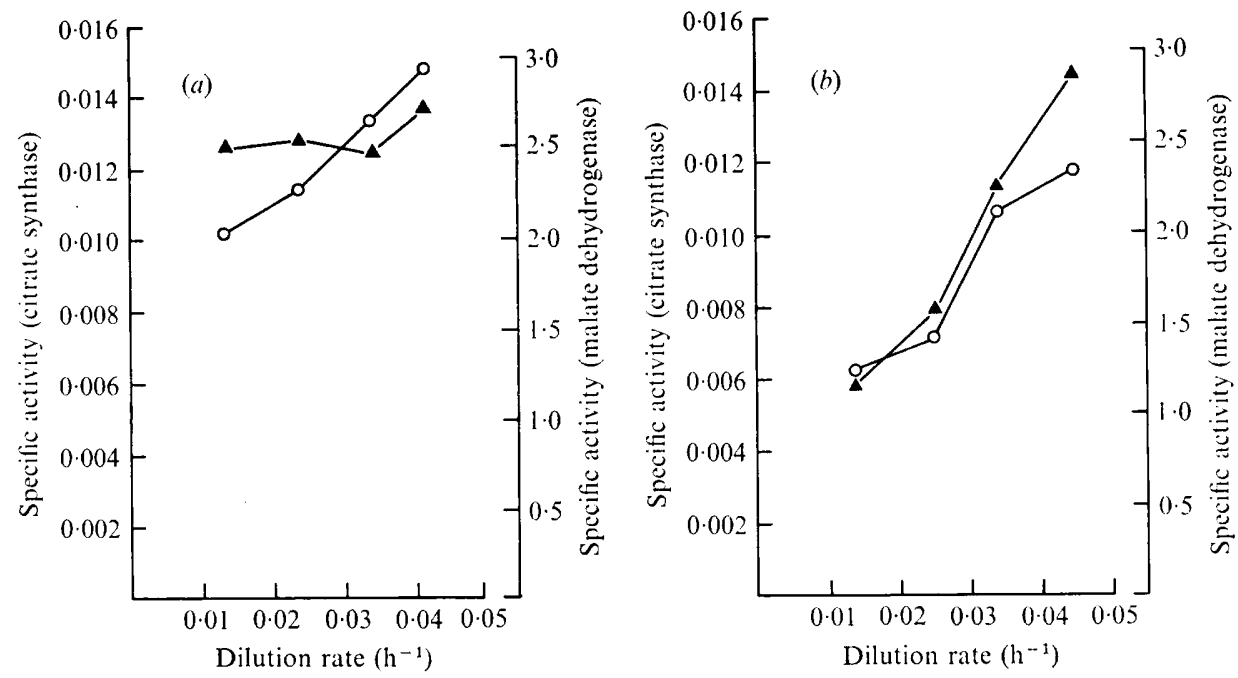

Fig. 2. Effect of dilution rate on the activity of citrate synthase and malate dehydrogenase of Aspergillus niger. Conditions as in Fig. I. А, Citrate synthase; $O$, malate dehydrogenase.

Activities of enzymes of the glyoxylate by-pass

Citrate limitation. The effect of dilution rate under citrate limitation on glyoxylate by-pass enzymes is shown in Fig. 3(a). Isocitrate lyase activity increased slightly between $D=0.013$ and $0.024 \mathrm{~h}^{-1}$ but then followed a sharp decrease to $D=0.042 \mathrm{~h}^{-1}$. The pattern of change in activity of malate synthetase was less pronounced than that of isocitrate lyase. Activity increased slightly as the dilution rate was increased from $D=0.013$ to $0.024 \mathrm{~h}^{-1}$ and then decreased to $D=0.042 \mathrm{~h}^{-1}$. 
Table I. Effect of dilution rate on biomass and residual citrate or glucose in citrate or glucose limiting chemostat culture of Aspergillus niger

\begin{tabular}{|c|c|c|c|c|}
\hline \multirow[b]{2}{*}{$\begin{array}{l}\text { Dilution } \\
\text { rate } \\
\left(\mathrm{h}^{-1}\right)\end{array}$} & \multicolumn{2}{|c|}{ Citrate limitation } & \multicolumn{2}{|c|}{ Glucose limitation } \\
\hline & $\begin{array}{c}\text { Biomass } \\
\text { (mg dry wt/ } \\
100 \mathrm{ml} \text { medium) }\end{array}$ & $\begin{array}{l}\text { Residual } \\
\text { citrate } \\
(\mathrm{g} / \mathrm{l})\end{array}$ & $\begin{array}{c}\text { Biomass } \\
\text { (mg dry wt/ } \\
\text { I00 ml medium) }\end{array}$ & $\begin{array}{l}\text { Residual } \\
\text { glucose } \\
(\mathrm{g} / \mathrm{l})\end{array}$ \\
\hline 0.012 & $99 \cdot 2$ & 0.22 & - & - \\
\hline 0.013 & - & - & 410.8 & 0 \\
\hline 0.020 & $132 \cdot 0$ & 0.21 & $466 \cdot 8$ & 0 \\
\hline 0.029 & $14 I \cdot 8$ & 0.21 & $460 \cdot 0$ & o \\
\hline 0.042 & $143 \cdot 2$ & 0.23 & - & - \\
\hline 0.045 & - & - & $468 \cdot 2$ & 0 \\
\hline $0.05 \mathrm{I}$ & 83.4 & $2 \cdot 54$ & - & - \\
\hline 0.060 & - & - & $464 \cdot 4$ & 0 \\
\hline 0.083 & - & - & $478 \cdot \mathrm{I}$ & o \\
\hline 0.102 & - & - & $300 \cdot 3$ & $I \cdot 72$ \\
\hline
\end{tabular}
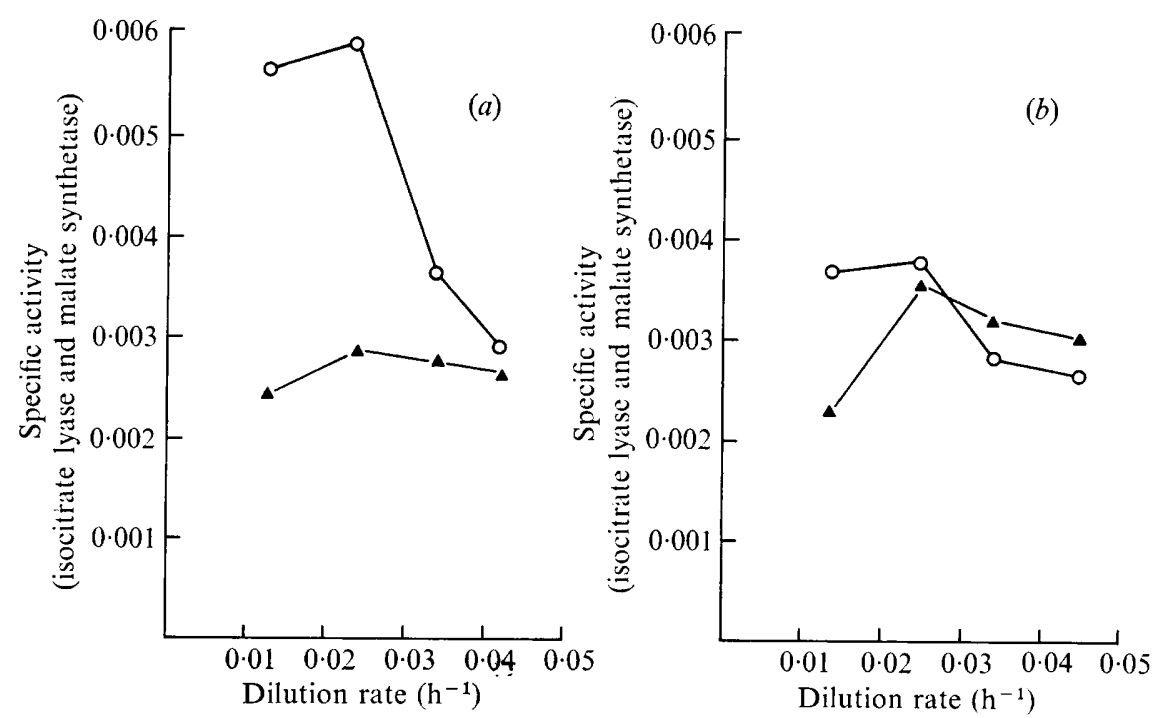

Fig. 3. Effect of dilution rate on the activity of isocitrate lyase and malate synthetase of Aspergillus niger. Conditions as in Fig. I. O, Isocitrate lyase; $\mathbf{\Lambda}$, malate synthetase.

Glucose limitation. The effect of dilution rate under glucose limitation on glyoxylate bypass enzymes is shown in Fig. $3(b)$. Isocitrate lyase activity varied less with dilution rate under glucose limitation than under citrate limitation. The activity varied little between $D=0.013$ and $0.024 \mathrm{~h}^{-1}$ and then decreased to $D=0.042 \mathrm{~h}^{-1}$. Malate synthetase responded in a manner similar to isocitrate lyase, except that a rather sharp increase occurred between $D=0.013$ and $0.024 \mathrm{~h}^{-1}$. The level of isocitrate lyase was higher in citrate limiting culture than in glucose limiting culture at similar dilution rates. However, there was no marked difference in malate synthetase activities between citrate limiting and glucose limiting cultures. 


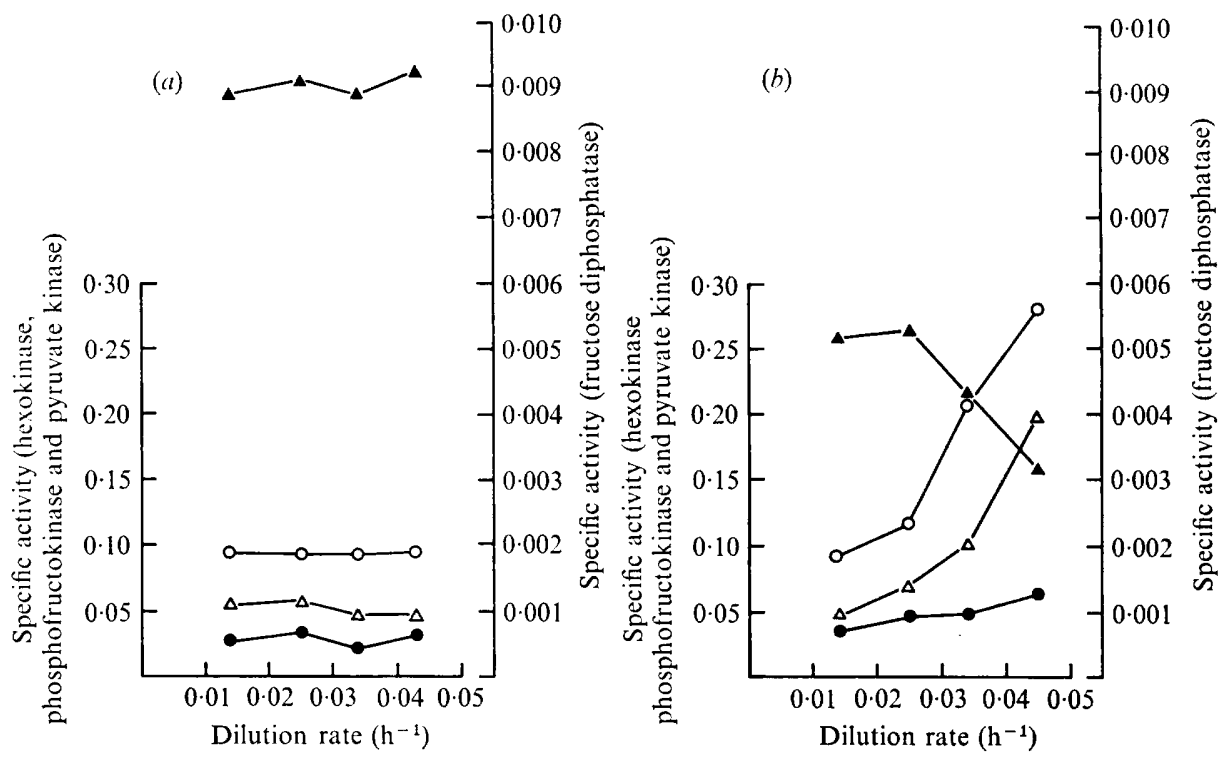

Fig. 4. Effect of dilution rate on the activity of hexokinase, phosphofructokinase, pyruvate kinase and fructose diphosphatase of Aspergillus niger. Conditions as in Fig. I. $O$, Hexokinase; $\triangle$, phosphofructokinase; $\bullet$, pyruvate kinase; $\boldsymbol{\Delta}$, fructose diphosphatase.
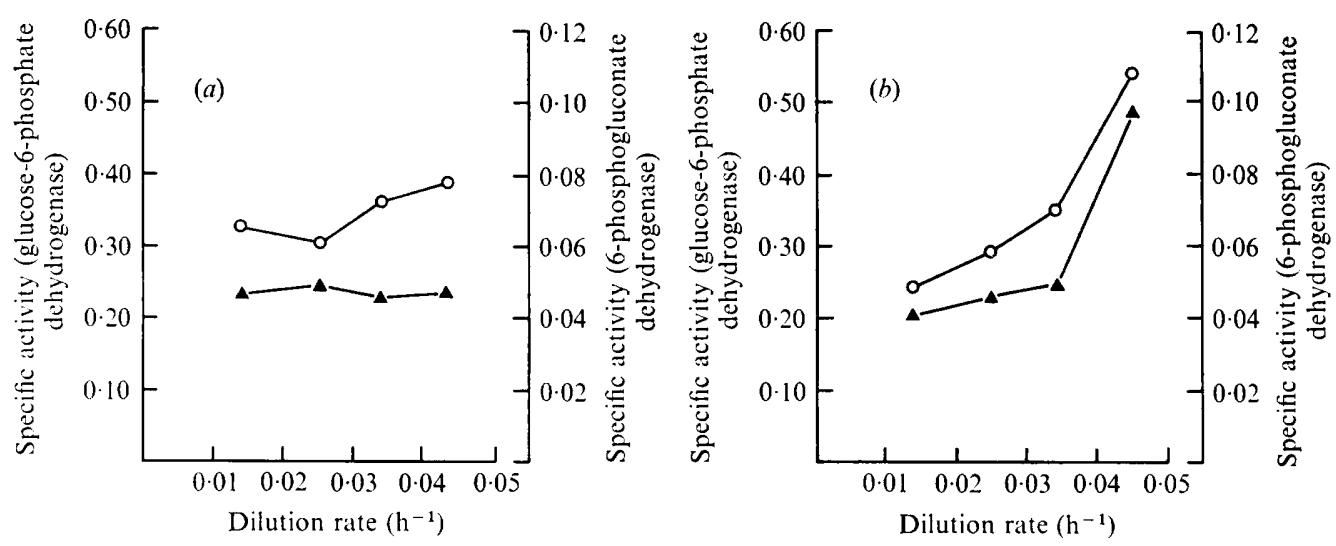

Fig. 5. Effect of dilution rate on the activity of glucose-6-phosphate dehydrogenase and 6-phosphogluconate dehydrogenase. Conditions as in Fig. I. O, Glucose-6-phosphate dehydrogenase; $\mathbf{\Delta ,} 6$ phosphogluconate dehydrogenase.

\section{Activities of enzymes of the Embden-Meyerhof-Parnas and pentose phosphate pathways}

Citrate limitation. The effect of dilution rate under citrate limitation of EMP and PP pathway enzymes is shown in Figs. 4(a) and 5(a). With the exception of phosphofructokinase and glucose-6-phosphate dehydrogenase there was little variation with change in dilution rate. Phosphofructokinase activity remained approximately constant between $D=0.014$ and $0.024 \mathrm{~h}^{-1}$, above which the activity fell slightly. Glucose-6-phosphate dehydrogenase 
activity showed little variation between $D=0.014$ and $0.024 \mathrm{~h}^{-1}$ but increased somewhat between $D=0.024$ and $0.043 \mathrm{~h}^{-1}$.

Glucose limitation. The effect of dilution rate under glucose limitation of EMP and PP pathway enzymes is shown in Figs. $4(b)$ and $5(b)$. Both hexokinase and phosphofructokinase increased rather sharply in activities with increasing dilution rates, although the specific activity of hexokinase was higher than that of phosphofructokinase throughout. Pyruvate kinase activity remained low and only increased slightly as the dilution rate was raised. Fructose diphosphatase was present only at trace level and exhibited a pattern of change opposite to that of phosphofructokinase. Activity decreased as the dilution rate was increased from $D=0.024$ to $0.042 \mathrm{~h}^{-1}$. Glucose-6-phosphate dehydrogenase activity varied directly with dilution rate, increasing the dilution rate from $D=0.014$ to $0.042 \mathrm{~h}^{-1}$ causing a twofold increase in activity. Change in activity of 6-phosphogluconate dehydrogenase followed a pattern similar to glucose-6-phosphate dehydrogenase except that the increase in activity between $D=0.014$ and $0.034 \mathrm{~h}^{-1}$ was comparatively slight.

Compared with citrate limiting culture, the activities of the enzymes of EMP pathway in glucose limiting culture were high whereas the activity of the gluconeogenic enzyme fructose diphosphatase was low. The activities of the two enzymes of the PP pathway differed mainly at the lowest and the highest dilution rates.

No inhibitors were detected in cell-free extracts in all assays performed.

\section{DISCUSSION}

Studies with Aspergillus niger have shown that under batch culture the levels of activity of enzymes of the TCA cycle, the glyoxylate by-pass, and the EMP and PP pathways vary depending on the environmental conditions and in particular the source of carbon $(\mathrm{Ng}$ et al. I972; Ng, Smith \& McIntosh, I973b). Under glucose limitation in chemostat culture, hexokinase, phosphofructokinase and pyruvate kinase varied directly with dilution rate as did glucose-6-phosphate dehydrogenase and 6-phosphogluconate dehydrogenase. These findings agree with the observations reported by Carter \& Bull (I969) for Aspergillus nidulans growing under glucose limitation in chemostat culture. Under glucose limitation all the TCA cycle enzymes measured increased in activity with increasing dilution rates. This agrees with the work of Carter, Bull, Pirt \& Rowley (197I), who showed that malate dehydrogenase and glutamate dehydrogenase activities were enhanced at high dilution rates in glucose limiting chemostat culture of $A$. nidulans, but is in contrast to glucose limiting chemostat culture of Saccharomyces cerevisiae (Beck \& von Meyenberg, I968).

Under citrate limitation all TCA cycle enzymes, with the exception of citrate synthase, varied directly with the dilution rate. Citrate synthase did not change appreciably at the various dilution rates and it is possible that some other non-limiting factor may be involved in the regulation of this enzyme. For the glucose catabolic enzymes, hexokinase, phosphofructokinase and pyruvate kinase were suppressed to a greater extent than glucose-6phosphate dehydrogenase and 6-phosphogluconate dehydrogenase. Thus the energygenerating capacity of glycolysis can be fulfilled by the TCA cycle whereas there is no substitute for the essential $\mathrm{NADPH}_{2}$ and pentose production role of the PP pathway.

Gluconeogenesis appears to be stimulated to a greater extent in citrate-limiting culture than in glucose limiting culture, as indicated by the higher activity of fructose diphosphatase in the former. However, the absolute value of the maximum activity of this enzyme is comparatively low. In batch culture of Aspergillus niger only trace amounts of this enzyme can be detected and it is possible that it has unusual properties and requires a special assay method ( $\mathrm{Ng}$ et al. 1972). 
Thus in glucose limiting chemostat culture all enzymes of the TCA cycle and EMP and PP pathways that were measured were derepressed and increased in activity with increasing growth rate. In citrate limiting culture the EMP and PP pathways were partially repressed, whereas the TCA cycle enzymes were all derepressed and with the exception of citrate synthase increased with increasing growth rate. Thus in Aspergillus niger the synthesis of certain EMP and PP pathway enzymes may be partly regulated by induction by glucose (or its metabolites) and repression by products of citrate metabolism. The role of nitrogen source and oxygen concentration must not be overlooked and warrants further study.

The lower level of the glyoxylate by-pass enzymes in glucose limiting culture may be due to the preferential formation of $\mathrm{C}_{4}$ skeletons by condensation of $\mathrm{C}_{3}$ compounds and $\mathrm{CO}_{2}$ (Wood-Werkman condensation). Clarke, Houldsworth \& Lilly (I968) have attempted to explain the occurrence of maximum values in specific enzyme activity in relation to dilution rate in $\mathrm{C}$-limiting culture in terms of a balance between induction and catabolic repression. At low dilution rates catabolite repression is minimal and the rate of enzyme synthesis is dependent mainly on the rate at which the substrate is presented to the organism. With increasing dilution rate the specific activity of the enzyme under steady-state conditions increases. However, above certain dilution rates the growth rate has increased to a point where metabolic intermediates are being formed at a rate sufficiently high to create significant catabolite repression. At these higher dilution rates catabolite repression becomes dominant and the specific activity of the enzyme decreases. In batch glucose/ammonia culture of Aspergillus niger ( $\mathrm{Ng}$ et al. $1973 \mathrm{~b}$ ) the glyoxylate by-pass enzymes were almost completely repressed but increased rapidly in specific activity when transferred to citrate medium.

Previous studies have shown that conidiation of Aspergillus niger can occur in citrate limiting chemostat culture ( $\mathrm{Ng}$ et al. 1973a). The number of free conidia in the culture medium decreases as the dilution rate increases. Conidiation was difficult to achieve in glucose limiting culture and did not occur above $D=0.013 \mathrm{~h}^{-1}$. At $D=0.013 \mathrm{~h}^{-1}$ conidiation occasionally occurred, while slightly better conidiation could be obtained when the dilution rate was lowered to $D=0.008 \mathrm{~h}^{-1}$. However, at this dilution rate steady-state conditions could not be maintained due to autolysis. When comparing enzyme activities at the dilution rates that support conidiation, higher activities of the PP pathway enzymes and isocitrate lyase are particularly noticeable in the citrate limiting culture. Such results show an interesting parallel with those already observed during conidiation in batch culture for A. niger (Galbraith \& Smith, $1969 b ; \mathrm{Ng}$ et al. 1972, 1973b).

The maximum specific growth rate in citrate limiting chemostat culture was $0.05 \mathrm{I} \mathrm{h}^{-1}$ and in batch culture $0.095 \mathrm{~h}^{-1}(\mathrm{Ng}, 1972)$. The low chemostat value may be due to the noticeable change that occurred in mycelial morphology as the dilution rate increased. Whereas in batch culture the mycelium was composed entirely of filaments, in chemostat culture at $D=0.05 \mathrm{I} \mathrm{h}^{-1}$ the mycelium was not homogeneous in the strict sense but rather a mixture of pellets and filaments. This onset of pellet formation would naturally favour 'wash-out'. Pellet formation was less apparent at the higher dilution rates in glucose limiting culture.

However, it is also possible that at these higher dilution rates growth could be limited by a trace metal. 


\section{REFERENCES}

ANDERSON, J. G. \& SMITH, J. E. (197I). Synchronous initiation and maturation of Aspergillus niger conidiophores in culture. Transactions of the British Mycological Society 56, 9-29.

ANFInsen, C. B. (1955). Aconitase from pig heart muscle. In Methods in Enzymology, vol. 1, pp. 698-699. Edited by S. P. Colowick and N. O. Kaplan. New York: Academic Press.

Bainbridge, B. W., Bull, A. T., Pirt, S. J., Rowley, B. I. \& Trinci, A. P. J. (I97I). Biochemical and structural changes in non-growing maintained and autolysing cultures of Aspergillus nidulans. Transactions of the British Mycological Society 56, 371-385.

BECK, C. \& VON MEYENBURG, H. K. (I968). Enzyme pattern and aerobic growth of Saccharomyces cerevisiae under various degrees of glucose limitation. Journal of Bacteriology 96, 479-486.

Bucher, T. \& Pfleiderer, G. (1955). Pyruvate kinase from muscle. In Methods in Enzymology, vol. I, pp. 435-44I. Edited by S. P. Colowick and N. O. Kaplan, New York: Academic Press.

CARTer, B. L. A. \& Bull, A. T. (1969). Studies of fungal growth and intermediary carbon metabolism under steady and non-steady state conditions. Biotechnology and Bioengineering Ir, 785-804.

Carter, B. L. A., Bull, A. T., Pirt, S. J. \& Rowley, B. I. (I97I). Relationship between energy substrate utilization and specific growth rate in Aspergillus nidulans. Journal of Bacteriology 108, 309-313.

Clarke, P. H., Houldsworth, M. A. \& Lilly, M. D. (1968). Catabolite repression and the induction of amidase synthesis by Pseudomonas aeruginosa 8602 in continuous culture. Journal of General Microbiology 51, 225-234.

Clarke, P. H. \& LILLY, M. D. (1969). The regulation of enzyme synthesis during growth. Symposia of the Society for General Microbiology 19, I I3-I 59.

Dean, A. C. R. (1972). Influence of environment on the control of enzyme synthesis. Journal of Applied Chemistry and Biotechnology 22, 245-259.

Dixon, G. H. \& Kornberg, H. L. (I959). Assay methods for key enzymes of the glyoxylate cycle. Biochemical Journal 72, 3 P.

Galbratth, J. C. \& Sмrth, J. E. (I969a). Sporulation of Aspergillus niger in submerged liquid culture. Journal of General Microbiology 59, 3 I-45.

GalbRaith, J. C. \& Smith, J. E. (I969 b). Changes in activity of certain enzymes of the tricarboxylic acid cycle and the glyoxylate cycle during the initiation of conidiation of Aspergillus niger. Canadian Journal of Microbiology 15, 1207-I 212.

GibBs, M. \& TURner, E. F. (I964). Enzymes of glycolysis. In Modern Methods of Plant Analysis, vol. 7, pp. 521-545. Berlin, Göttingen and Heidelberg: Springer-Verlag.

Hock, B. \& BeEvers, H. (I966). Development and decline of the glyoxylate cycle in watermelon seedlings (Citrillus vulgaris Schrad.). Effects of actinomycin D and cycloheximide. Pflanzenphysiologie 55, 405-4I4.

HoreCKer, B. L. \& KornberG, A. (1948). The extinction coefficients of the reduced band of pyridine nucleotides. Journal of Biological Chemistry $\mathbf{1 7 5}, 385-390$.

Khouw, B. T. \& MCCurdy, H. D. (1969). Tricarboxylic acid cycle enzymes and morphogenesis in Blastocladiella emersonii. Journal of Bacteriology 99, I97-205.

KoRnBerg, A. (1955). Isocitrate dehydrogenase of yeast. In Methods in Enzymology, vol, I, pp. 705-706. Edited by S. P. Colowick and N. O. Kaplan. New York: Academic Press.

Lowry, O. H., Rosebrough, N. J., FARr, A. L. \& Randall, R. J. (I95I). Protein measurement with Folin phenol reagent. Journal of Biological Chemistry 193, 265-275.

NG, A. M. L. (1972). Physiological and biochemical aspects of conidiation of Aspergillus niger under batch and continuous culture. Ph.D. thesis, University of Strathclyde, Glasgow.

Ng, A. M. L., Smith, J. E. \& McIntosh, A. F. (I973a). Conidiation of Aspergillus niger in continuous culture. Archiv für Mikrobiologie 88, 1 19-1 26.

NG, A. M. L., Smith, J. E. \& McIntosh, A. F. (1973 $b$ ). Changes in activity of tricarboxylic acid cycle and glyoxylate cycle enzymes during synchronous development of Aspergillus niger. Transactions of the British Mycological Society, 6r, 13-20.

NG, W. S., SMITH, J. E. \& ANDERSON, J. G. (1972). Changes in carbon catabolic pathways during synchronous development of conidiophores of Aspergillus niger. Journal of General Microbiology 7I, 495-504.

OCHOA, S. (1955). Malic dehydrogenase from pig heart. In Methods in Enzymology, vol. I, pp. 735-753. Edited by S. P. Colowick and N. O. Kaplan. New York: Academic Press.

Rosen, O. M. (1966). Purification and properties of fructose-I,6-diphosphatase from Polysphondylium pallidum. Archives of Biochemistry and Biophysics 114, 3 I-37.

SAFFran, M. \& DenstedT, O. F. (1948). A rapid method for the determination of citric acid. Journal of Biological Chemistry 175, 849-855. 
SLATER, E. C. (1953). Spectrophotometric determination of fructose-I,6-diphosphate, hexosemonophosphates, adenosinetriphosphate and adenosinediphosphate. Biochemical Journal 52, I57-167.

SRERE, P. A. \& KosICKI, G. W. (1961). The purification of the citrate condensing enzyme. Journal of Biological Chemistry 236, 2557-2570.

von Tigerstrom, M. \& CAMpbell, J. J. R. (1966). The accumulation of $\alpha$-ketoglutarate by suspensions of Pseudomonas aeruginosa. Canadian Journal of Microbiology 12, 1005-1013.

WAYGOOD, E. R. \& RoHRINGER, R. (1964). Enzymes of the pentose pathway. In Modern Methods of Plant Analysis, vol. 7, pp. 546-568. Berlin, Göttingen and Heidelberg: Springer Verlag. 